\title{
Tackling the frailty burden with an integrative value-based approach: results from a mixed-methods study
}

\author{
Daniel Fürstenau ${ }^{1,2}$ (D) $\cdot$ Hannah Haneke ${ }^{3}$ Claudia Spies $^{4} \cdot$ Tim Walz $^{5} \cdot$ Kai Schewina $^{5} \cdot$ Moritz Höft $^{4} \cdot$ Rudolf Mörgeli $^{4}$. \\ Felix Balzer²
}

Received: 1 October 2020 / Accepted: 17 August 2021 / Published online: 17 September 2021

(C) The Author(s) 2021

\begin{abstract}
Aim The purpose of this paper is to investigate the implementation of value-based care principles in the context of frailty in the perioperative process, highlighting the importance of an integrative perspective considering medical and patient-centric outcomes as well as costs.

Subject and methods This mixed-methods study employs a sequential design. Qualitative observational data were used to identify needs and barriers for implementing value-based principles, and quantitative methods were subsequently used to demonstrate the value of employing such an approach using data gathered from $n=952$ patients. Propensity score matching was applied to identify the frailty-associated costs of the inpatient setting for $n=381$ non-frail and $n=381$ (pre-)frail patients, in particular considering patient-centric outcomes.

Results The qualitative analysis identified three main challenges when implementing value-based principles in the context of perioperative care and frailty, namely challenges related to the cost, patient-centric, and integrative perspectives. In addressing these shortcomings, a quantitative analysis of a propensity score-matched sample of patients undergoing surgery shows additional frailty-associated costs of 3583.01 [1654.92; 5511.04] EUR for (pre-)frail patients and the influence of individual patientcentric attributes. Effect size Cohen's $d$ was 0.26 .

Conclusion The results demonstrate that frailty should be considered from an integrative perspective, taking cost, patientcentered outcomes, and medical outcomes into account simultaneously. The results also show the value of a research design which uses qualitative data for the identification of needs and barriers, as well as quantitative data for demonstrating the usefulness of the conceived value-based approach to perioperative care delivery.
\end{abstract}

Keywords Frailty $\cdot$ Value-based health care $\cdot$ Digital health solutions $\cdot$ Barriers $\cdot$ Perioperative process $\cdot$ Integrative approach

Daniel Fürstenau

dfu.digi@cbs.dk

1 Department of Digitalization, Copenhagen Busines School, Howitzvej 60, 2000 Frederiksberg, Denmark

2 Institute of Medical Informatics, Charité - Universitätsmedizin Berlin, Charitéplatz 1, 10117 Berlin, Germany

3 Department Value-Based Health Care, Charité - Universitätsmedizin Berlin, Charitéplatz 1, 10117 Berlin, Germany

4 Department of Anaesthesiology and Intensive Care Medicine, Charité - Universitätsmedizin Berlin, Charitéplatz 1,

10117 Berlin, Germany

5 Department Wirtschaftsinformatik, Freie Universität Berlin, Garystr. 21, 14195 Berlin, Germany

\section{Introduction}

Frailty is a multidimensional syndrome commonly occurring among elderly people, which manifests itself through an increased vulnerability to stressors, which results in ageassociated decline of one's physical and psychological reserves (Xue 2011). Research on frailty, and especially frailty-associated complications, has been increasingly referred to, underlining its importance for evaluating and enhancing the functional status of patients in situations associated with great stressors. While aging is inescapable, recent findings suggest that frailty may quite well be, at least partly, preventable and can be potentially corrected through exercise and pre-rehabilitation training (Liu and Fielding 2011), better nutrition (Chaudhary 2018), and psychosocial support (Freitag and Schmidt 2016; Dent and Hoogendijk 2014). An accurate risk stratification is crucial in developing a better 
understanding of the individual physical and psychological resources of patients in critical situations (Birkelbach et al. 2019).

Surgeries and the corresponding perioperative care cycle are among the most psychologically and physiologically stressful conditions. In Germany, approximately 16.9 million patients undergo surgical procedures each year, and almost half of these are performed among patients over the age of 65, a range of the population especially prone to frailty (Statistisches Bundesamt 2018). As pointed out, frailty is a problem in the perioperative process due to increased risk from anesthesia such as delirium, as well as an increased risk of dementia, cognitive dysfunction, and other conditions (Feinkohl et al. 2017; Winterer et al. 2018). Frailty is also associated with higher occurrence of surgical-related complications, including the need to be discharged to an ICU, deeper sedation, and breathing aidsthereby substantially increasing the risk of worsened postoperative outcomes (Birkelbach et al. 2019).

Having the demographic change in mind, frailty should be recognized as a critical area not only for an individual's outcome in a perioperative setting but also for its importance in public health (Buckinx et al. 2015; Birkelbach et al. 2017). The perioperative process encompasses multiple stakeholders and steps (Fürstenau et al. 2019), which include: admission to the hospital by one's general practitioner or specialist, in-patient routing in the hospital, pre-operation planning and operation, postoperative patient routing in ICU or ward, patient release and ambulatory or rehabilitation care. Given this spectrum of care, frailty is thereby associated not only with worsened medical outcomes. It is also associated with high costs, as studies such as that of Sirven and Rapp (2017) for the French health care system context have shown, and with worsened individual patient outcomes.

Reorganizing care around patients in an efficient and effective manner can be realized with a value-based health care approach, supported by digital health solutions. The overarching goal is defined as achieving the best outcomes while lowering the costs, thereby maximizing value for the patients themselves (Porter and Teisberg 2006). One part of the equation is to evaluate outcomes that matter to patients. Patient-reported outcome measures (PROMs), documented by the patients themselves, aim at covering dimensions that reflect the individual's holistic health status serve as crucial measures. Validated and standardized outcome sets, as the ones provided by ICHOM, the International Consortium of Health Outcome Measures, consider frailty to be an important dimension of the clinical status of an elderly person (ICHOM 2021). Most studies have solely analyzed the usability and implementation of PROMs in certain contexts, which is of high importance. We argue, however, that efficiently tackling burden of disease requires integrative studies considering both parts of the equation. Often, the economic perspective is separated from the outcomes created which poses constraints to estimating real patient value.

Care quality is multidimensional, as is the life of an elderly person suffering from frailty who needs to undergo surgery.
Thus, a holistic evaluation of care quality and implementation of digital solutions requires integrating all indicators and combining them instead of solely analyzing specific aspects. We assume that digital solutions embedded in a value-enhancing infrastructure should be initially designed around the patients' needs. Even when considering a patient-centric approach, many promising digital health innovations are not transferred to clinical reality. In particular, approaches such as ours that involve the integration of care face several barriers to implementation (van Dyk 2014; Harst et al. 2019), namely economic, technical, end-user acceptance, and organizational barriers. These barriers hold back unlocking value for patients and should be considered when designing and implementing digital health solutions. While there has been extensive research into these barriers, we still a have limited understanding of how to overcome them, unlocking the ability of health care organizations to realize patient value using digital health solutions in general and in the context of frail patients.

The purpose of this paper is to investigate the implementation of value-based health care principles in the context of frailty in the perioperative process. Our study aims at providing evidence that analyzing interdependencies between all variables requires valuing not only medical outcomes, but also the patient perspective in terms of satisfaction and costs at the same time. The Charité-Universitätsmedizin Berlin, one of Europe's largest university hospitals, has recently increased their drive toward value-based health care by launching multiple initiatives (e.g., Karsten et al. 2018; Dewey 2018). The Department of Anesthesiology and Intensive Care Medicine has implemented a special track for elderly patients scheduled for elective surgery. This track includes a frailty assessment procedure for patients over 65 years of age. The implemented digital health solutions consisted of the core of an extension in a digital study database (REDCap) as well as subsequently the incorporation of the functionality into the patient data management system (PDMS, COPRA) for routine treatment in elderly patients scheduled for surgery. Furthermore, clinical decision support functionality in the form of an overview dashboard using a traffic light style was incorporated into the electronic medical record (EMR) system (SAP i.s.h. med). Further solutions (e.g., a self-assessment app) have been prototyped. At the heart of the implementation is a digital frailty assessment form in combination with analytical scoring methods.

\section{Methods}

This sequential mixed-methods study (Creswell and Creswell 2018) builds upon and uses data from a retrospective observational study performed at Charité's Department of Anesthesiology and Intensive Care Medicine (see Birkelbach et al. 2019), where a frailty assessment procedure was implemented in 2016 and 2017 (Frail-Amb, EA1/227/ 
16). This is a revelatory case due to its high number of stakeholder interfaces, superior level of professionalism, and use of (state-of-the-art) best practices and process guidelines with the goal to learn and improve upon. It is also a good environment to study both the obstacles towards implementing value-based principles and how they have been dealt with up to now. The study by Birkelbach et al. (2019) focused on medical outcomes and found that the rate of complications for elderly surgical patients was significantly higher in the pre-frail $(34.7 \%)$ and frail groups $(47.4 \%)$ as compared to the nonfrail group $(27.5 \%)$.

A sequential mixed-methods design, one in which qualitative data are collected before the quantitative data, analyzed separately, subsequently informing the quantitative study, was most suitable to consider the implementation of value-based principles vis-à-vis digital health solutions in the context of improving patient value in perioperative care processes for elderly people. Our study design firstly qualitatively considers the needs and barriers facing implementing a value-based health care approach. Based thereupon, quantitatively demonstrating the value of such an approach, we have considered three main building blocks of its implementation as shown in Fig. 1, namely the cost perspective, the patient-centric perspective, and the integrative perspective.

Qualitative data collection and analytical strategy Before analyzing and integrating the cost and individual patientreported measures, we collected qualitative data on the barriers to unlock patient value under the current approach. Qualitative data on the implementation were collected within members of the research team consisting of a digitalization researcher (first author), bringing an outside perspective, and anesthesiologist/informatics researcher (last author), who led the implementation, and was complemented by efforts from student thesis/research assistants. Other members of the research team were involved in providing feedback from different perspectives, including anesthesiology (third author), controlling (fifth author), and geriatrics (seventh author). Since we were involved in the implementation ourselves, we could conduct action research (Baskerville 1999) using both participatory and observational methods and data (Becker and Geer 1957), which had the advantage of giving us direct access to practices and behaviors, such as solution conception or design. These data were collected between 2017 and 2019 at several occasions, including field events, planning sessions, and workshops.

Table 1 displays qualitative field data that were collected from the three perspectives of costs, patient-centric viewpoints, and integrative viewpoints. Written field notes were maintained and analyzed to find any noted hurdles during the implementation of the approach. A note-taking tool was used by the first author, where main events, conversations within the research team, screenshots of the implementation, and other materials were stored. For the analysis, the material was structured by the first author using tabular formats, extracting main themes from the textual data. Regular discussions were held between the first and second author to iteratively refine the insights by going back and forth between data and (value-based health care) theory. We referred to advice on qualitative data analysis (Miles and Huberman 1994), creating tabular descriptions of main stakeholders (anesthesiologists, nurses, medical secretaries, IT employees) and their stances toward the approach's implementation as well as practical case narratives (Langley 1999; Cloutier and Langley 2020) showing the temporal progression of the implementation. For this paper, we have consolidated the findings into three main challenge areas, namely a missing cost perspective, lack of a patient-centric perspective, and a missing integrative perspective.

\section{Quantitative data collection and analytical strategy} Extending the results on medical outcomes (Birkelbach et al. 2019), the current study has gathered data for patients undergoing elective surgery with diagnosis-related group (DRG; Schreyögg et al. 2006) inpatient treatment cost data from the hospital's electronic health record system, which could serve as a blueprint for continuous analysis of costs and outcome. This analysis does not include patients with emergency procedures, procedures without anesthesia contribution or operation, multiple assessments, cancelled operation, or cardiac surgery. The integration of both medical and economic data enabled us to perform analyses which detailed the economics of inpatient treatment for frail patients in the essentially common and stressful context of surgical procedures.
Previous stud

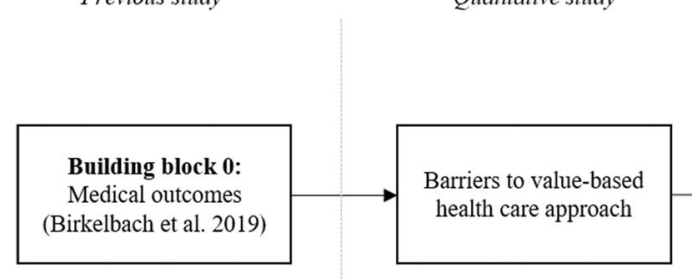

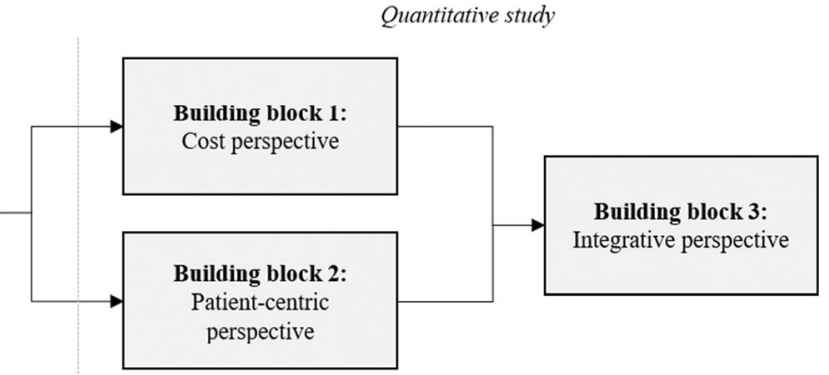

Fig. 1 Study design illustrating main blocks of a value-based health care approach 
Table 1 Qualitative data overview

\begin{tabular}{|c|c|c|}
\hline Perspective & Description & Sample data \\
\hline $\begin{array}{l}\text { Cost } \\
\text { perspective }\end{array}$ & $\begin{array}{l}\text { Observational data from collecting the data, setting up the } \\
\text { database, and performing and presenting the analysis }\end{array}$ & $\begin{array}{l}\text { - Memos from data comprehension sessions with the clinic's controlling } \\
\text { unit ( } 2 \text { interactions) } \\
\text { - Memos from data entry observations by student thesis researcher (1 } \\
\text { interaction) } \\
\text { - Internal documentation on clinical information system controlling } \\
\text { module (archival data) } \\
\text { - Joint sessions (first, third, last author) to develop scenarios to } \\
\text { demonstrate the usefulness of a cost perspective ( } 3 \text { interactions) }\end{array}$ \\
\hline $\begin{array}{l}\text { Patient-centric } \\
\text { perspective }\end{array}$ & $\begin{array}{l}\text { Observational data from close interactions within the research } \\
\text { team, including with the leader of implementation }\end{array}$ & $\begin{array}{l}\text { - Presentation and feedback from a workshop of student thesis } \\
\text { researcher with several members of the research team ( } 1 \text { interaction) } \\
\text { - Thesis report on mockup for patient self-assessment app (archival } \\
\text { data) }\end{array}$ \\
\hline $\begin{array}{l}\text { Integrative } \\
\text { perspective }\end{array}$ & $\begin{array}{l}\text { Observational data from close interactions within the research } \\
\text { team, including with the leader of implementation }\end{array}$ & $\begin{array}{l}\text { - Memos from discussions within research team, including } \\
\text { implementation leader ( } 5 \text { interactions) } \\
\text { - Notes from kick-off session of project focusing on rehabilitation in } \\
\text { perioperative care ( } 1 \text { interaction) } \\
\text { - Memos from further observations and interactions }\end{array}$ \\
\hline
\end{tabular}

Data was collected from $N=952$ individual patients between June 2016 and March 2017 during routine frailty assessment and inpatient treatment. The selection of patients for the frailty assessment followed several steps, namely, screening ( $n=15,376$ patients), frailty assessment ( $n=1502$ patients), enrolled patients ( $n=1455)$, and excluding patients with multiple assessments (a flowchart with detailed selection criteria is given in Appendix 1). Of these patients, $n=952$ patients were included in our analysis when cost and frailty assessment data was simultaneously available. The assessment consisted of a set of validated questions following the Fried criteria of physical, social, and psychological resources (Fried et al. 2001). The questionnaire data was collected by medical students and nurses. Patients were categorized into non-frail, pre-frail, and frail status; for the presented analysis we considered the differences between non-frail and both prefrail and frail patients, whereas we combined the two latter groups (pre-frail and frail) into one (pre-)frail group which was considered sufficient for our purpose (see also Dedeyne et al. 2017 for a review outlining studies that have done the same). We decided to group them as our qualitative study shows that in clinical reality, distinguishing between prefrail and frail patients poses critical barriers in terms of a too high degree of complexity and limited clinical advantage for the patients themselves. General patient information also available from the questionnaire included age, sex, body mass index (BMI), smoking status, and polypharmacy defined as routine intake of $>5$ medications per day. Further, the Barthel Index (Mahoney and Barthel 1965), which was extracted from the electronic health record system, was determined for each patient reflecting on the individual's ability for fulfilling activities of daily living with or without help. Comorbidities were calculated with help of the Charlson Comorbidity Index (CCI) (Charlson et al. 1987).
We determined the frailty-associated costs in the inpatient environment through a cost-economic evaluation of the data set. A first analysis considered the cost perspective testing for differences across non-frail and (pre-)frail patients. Comparisons of the two groups considered mean differences and used unpaired $t$-tests. Differences were considered statistically significant at $p$ $<0.05$, and all analyses were two-tailed. All confidence intervals are reported at the $95 \%$ level.

A second analysis followed considering the individual patient perspective in more detail. A variable was chosen in order to reflect an important aspect of the "quality of life" dimension of the ICHOM standard set for an older person. We considered happiness (binary coded as 1 if the person indicated happiness during assessment). We used logistic regression due to the binary nature of this variable and our intent to explore covariates and influences.

In a third step, we analyzed the integrative perspective in which we considered costs, frailty status, individual patient-reported health information, and other covariates. We analyzed the data using $\mathrm{R}$ package (version 4.0.2, https://www.r-project.org/) and SPSS 22.0 for Windows (IBM Corp., Armonk, NY, USA). For propensity score matching, we used the SPSS PS-Matching 3.0.2 package, with 1:1 matching using variables age, gender, BMI, Barthel Index, CCI, surgical discipline, smoking status, polypharmacy, complications, length of stay (LoS), and happiness as covariates. The variables for PS-score matching were selected based on consistency with prior analyses (especially Birkelbach et al. 2019), comprehensiveness, and domain-based reasoning. We used paired $t$ tests with independent samples to show similarity of variables across the matched data. We compared costs for matched data using independent-sample paired $t$-tests. 


\section{Results}

\section{Qualitative results}

Our observational data confirmed three main challenges regarding unlocking real patient value of the value-based approach considering frailty in the perioperative process, namely (1) a missing cost perspective, (2) lacking patientcenteredness of the approach, and (3) a missing integrative perspective (see Table 2). Using the categorization by Harst et al. (2019), these barriers can be categorized using previously identified barriers to the implementation of digital health solutions, thereby opening up the opportunity to embed data in a broader analytical context.

Missing cost perspective While the preceding analysis by Birkelbach et al. (2019) had demonstrated the value of frailty assessment for explaining important medical outcomes such as complications and length of stay, the approach was not yet linked to a financial perspective, which limited insights into the economic implications of frailty in the perioperative process. Our observational data confirmed that such a perspective would be valuable, especially as clinic controlling and medical professionals are working towards maintaining a more integrative view of care delivery. While striving for extending value-based care delivery, economic concerns often serve as driving forces for realizing innovational change. Considering and linking the cost perspective with outcomes builds a fundamental for designing and creating new reimbursement structures serving as incentives for various players to support value-based care models.

This, however, called for combining gathered data from surgical patients undergoing the frailty assessment with actual cost data from clinic controlling. The cost perspective is linked to DRG data, which determines reimbursement for treatment based on diagnosis and related severity degrees as well as other discounting factors. This data is complemented by internal cost accounting data which allows the care deliverer, which in our case is the hospital, the determination of treatment margins when costs are deducted from the compensation received. This data is typically sensitive since it gives insight into both patient treatment and competitive corporate data. Using such data for our research meant gaining the obligatory permits and pseudonymizing the data.

Lacking patient-centeredness of the approach The initial assessment tool was accessible only as paper-based. Early in the project to implement the assessment, the team had complemented the paper-based forms with a study database using the REDCap tool. REDCap is a community-based digital health solution consisting of a database used primarily for clinical and translational research purposes, having a browserbased interface for data entry (Harris et al. 2009). Later, the assessment was also integrated into the patient data management system of the Anesthesiology Department, allowing it to be used as a stationary desktop solution by nurses and nurse assistants for entering the test results as well as the hospital's electronic health record system. However, the desktop solution could not be used at the bedside and was restricted to working hours. This could pose constraints to our target population, as frailty often correlates with decreased mobility. In response, we created the concept for a tablet app for medical personnel to be used for full-scale assessment at bedside.

Moreover, it lacked a patient self-assessment, inconsistent with our goal of putting patients center stage. We also conceptualized a patient self-assessment app based on a basic validated set of questions (i.e., Tilburg frailty indicator; Freitag et al. 2016), which could be used when the patient is entering the hospital and potentially be extended to home usage after discharge. By linking the full-scale frailty assessment with a self-assessment, we aimed at considering the patients' perspective even more and to facilitate early stratification. In this study, we use questions from the original assessment, namely happiness status, offering a starting point for further extending disease-related patient-reported outcomes.

Table 2 Identified challenges

\begin{tabular}{|c|c|c|}
\hline Challenge & Description & Category according to Harst et al. (2019) \\
\hline 1) Missing cost perspective & $\begin{array}{l}\text { - Missing purview of the economic implications resulting } \\
\text { from frailty-related costs and thereby limiting financial value } \\
\text { created by the approach }\end{array}$ & Economic \\
\hline $\begin{array}{l}\text { 2) Lacking patient-centeredness of the } \\
\text { approach }\end{array}$ & $\begin{array}{l}\text { - Limited questions regarding patient status in initial assessment } \\
\text { - Stationary assessment solutions cannot be used at bedside } \\
\text { setting, nor outside office hours }\end{array}$ & End-user acceptance and technical \\
\hline 3) Missing integrative perspective & $\begin{array}{l}\text { - Missing overview of combined patient status across all } \\
\text { dimensions of the value-based approach (i.e., medical, } \\
\text { patient, and cost perspective) } \\
\text { - Data is too spread out in different information systems }\end{array}$ & Organizational and technical \\
\hline
\end{tabular}


Missing integrative perspective A further challenge was bringing these different perspectives together to promote a holistic understanding of care cycles. While medical outcomes, costs, and patient-centric outcomes are considered separately in most studies (Porter and Teisberg 2006; Porter 2008), the premise of our work is that the highest patient value arises if an integrative approach is chosen. To do so, several challenges need to be overcome or coped with that can be classified as organizational and technical. Organizationally, the perioperative process involves several clinical units and sub-disciplines such as surgical departments, anesthesiology and intensive care, rehabilitation, and more. Technically, data on medical outcomes, costs, and patient-centric outcomes is spread across different information systems requiring integration. In part, the project had to establish the respective measurement approaches first before they could be considered in an integrative way. Moreover, data structures and formats needed to be aligned in order to create an integrative analysis. While our subsequent work demonstrates potentials of doing so, further work will be necessary to fully consider the integrative perspective in daily routine on a continued basis. This will also create the baseline for interventional improvements of routine practice in an evidence-based way following the principles of valuebased health care.

\section{Quantitative results}

As shown in Table 3, in the study data set the prevalence of (pre-)frailty status was $60.0 \%$, of which $11.8 \%$ were frail and $48.2 \%$ were pre-frail. The average age was 73.53 years. The study population was $52.9 \%$ male. The average BMI was 26.81, Barthel Index 93.60, and CCI 3. Of the patients, the most prevalent procedures underwent were: orthopedic (31.6\%), followed by urology, otorhinolaryngology, general/ visceral, gynecology, and others. In our sample, $14.8 \%$ of the patients were active smokers, and $47.2 \%$ reported polypharmacy;. $85.66 \%$ of the patients reported that they were happy.

\section{Building block 1: Cost perspective}

The results show that the clinical frailty status is associated with significantly higher in-patient treatment costs across several categories of age, gender, BMI, Barthel Index, CCI, surgical discipline, smoking status, polypharmacy, and happiness. As can be seen in Table 4, average treatment costs were higher across all categories for (pre-)frail patients (except for urology patients). Having a look at the total sample, (pre-)frail patients on average cost 4024.01 EUR more than non-frail patients undergoing surgery.
Table 3 Descriptive statistics on the frailty cost data set

\begin{tabular}{ll}
\hline Data set characteristics & $n=952$ \\
\hline Age & $73.53[73.19 ; 73.89]$ \\
Male & $504(52.9 \%)$ \\
BMI & $26.81[26.50 ; 27.11]$ \\
Barthel Index & $93.60[92.74 ; 94.46]$ \\
CCI & $3.00[2.82 ; 3.18]$ \\
Surgical discipline & \\
Orthopedic & $301(31.6 \%)$ \\
Urology & $214(22.5 \%)$ \\
Otorhinolaryngology & $165(17.3 \%)$ \\
General/visceral & $162(17.0 \%)$ \\
Gynecology & $80(8.4 \%)$ \\
Other & $30(3.2 \%)$ \\
Smoking status & \\
Yes, active & $141(14.8 \%)$ \\
No, quit & $333(35.0 \%)$ \\
No, never & $478(50.2 \%)$ \\
Polypharmacy (>5 drugs) & $449(47.2 \%)$ \\
Happy & $816(85.7 \%)$ \\
Non-frail & $381(40.0 \%)$ \\
Frailty status, among: & $571(60.0 \%)$ \\
Pre-frail & $459(48.2 \%)$ \\
Frail & $112(11.8 \%)$ \\
\hline
\end{tabular}

For age, BMI, Barthel, and CCI: Mean and in square brackets [] 95\% confidence interval are given

\section{Building block 2: Patient-centric perspective}

The results in Table 5 display that the distribution of happiness on the individual level is different across frailty categories. It can be seen that while happiness was generally more prevalent in the data set, (pre-)frail people tended to be less happy.

Table 6 applies logistic regression to happiness as dependent variable. The analysis showed that (pre-)frailty status is associated with decreased happiness. The odds ratio was 0.352 for (pre-)frailty status on happiness. The model also explained a relevant portion of variance in happiness and increased against a control-only model (pseudo- $R^{2}=0.098$ ). This result suggests that frailty status is an important factor when considering the individual patient perspective.

\section{Building block 3: Integrative perspective}

Considering an integrative perspective, we performed a propensity score matching with age, gender, BMI, Barthel Index, CCI, surgical discipline, smoking status, polypharmacy, complications, length of stay (LoS), and happiness as covariates. The resulting matched samples of (pre-)frail versus non-frail patients are displayed in Table 7. The matched sample diverged in significant characteristics of interest: (pre-)frail 
Table 4 Frailty-associated costs across patient groups in study sample

\begin{tabular}{|c|c|c|c|c|c|}
\hline & & \multicolumn{3}{|l|}{ Costs } & \multirow[b]{2}{*}{$p$ value } \\
\hline & & Total & Non-frail & (Pre-)frail & \\
\hline \multirow[t]{5}{*}{ Age } & $65-69$ & $\begin{array}{l}9224.39 \\
{[6300.41 ; 12,148.37]}\end{array}$ & $\begin{array}{l}7086.88 \\
{[4966.50 ; 9207.26]}\end{array}$ & $\begin{array}{l}11,497.61 \\
{[5883.56 ; 17,111.67]}\end{array}$ & 0.148 \\
\hline & $70-74$ & $\begin{array}{l}7847.19 \\
{[5799.39 ; 9894.99]}\end{array}$ & $\begin{array}{l}5896.49 \\
{[4669.42 ; 7123.56]}\end{array}$ & $\begin{array}{l}9574.53 \\
{[5869.51 ; 13,279.54]}\end{array}$ & 0.077 \\
\hline & $75-79$ & $\begin{array}{l}8648.43 \\
{[7068.74 ; 10,228.12]}\end{array}$ & $\begin{array}{l}6215.11 \\
{[4861.35 ; 7568.86]}\end{array}$ & $\begin{array}{l}9760.43 \\
{[7553.37 ; 11,967.49]}\end{array}$ & 0.007 \\
\hline & $80-84$ & $\begin{array}{l}12,178.76 \\
{[8111.28 ; 16,246.24]}\end{array}$ & $\begin{array}{l}6400.33 \\
{[3481.50 ; 9319.17]}\end{array}$ & $\begin{array}{l}13,796.72 \\
{[8682.41 ; 18,911.03]}\end{array}$ & 0.136 \\
\hline & $85+$ & $\begin{array}{l}7799.72 \\
{[5689.75 ; 9909.69]}\end{array}$ & $\begin{array}{l}4381.00 \\
\text { [n.a.;n.a.] }\end{array}$ & $\begin{array}{l}7910.00 \\
{[5740.32 ; 10,079.68]}\end{array}$ & 0.561 \\
\hline \multirow[t]{2}{*}{ Gender } & Male & $\begin{array}{l}8946.72 \\
{[7168.91 ; 10,724.52]}\end{array}$ & $\begin{array}{l}6325.47 \\
{[5477.72 ; 7173.22]}\end{array}$ & $\begin{array}{l}11,026.92 \\
{[7922.68 ; 14,131.16]}\end{array}$ & 0.004 \\
\hline & Female & $\begin{array}{l}8654.38 \\
{[7294.62 ; 10,014.14]}\end{array}$ & $\begin{array}{l}6494.54 \\
{[4680.94 ; 8308.15]}\end{array}$ & $\begin{array}{l}9831.12 \\
{[7984.02 ; 11,678.21]}\end{array}$ & 0.011 \\
\hline \multirow[t]{2}{*}{ BMI } & $>26$ & $\begin{array}{l}8879.22 \\
{[7565.84 ; 10,192.61]}\end{array}$ & $\begin{array}{l}6744.81 \\
{[5731.34 ; 7758.28]}\end{array}$ & $\begin{array}{l}10,190.57 \\
{[8172.48 ; 12,208.65]}\end{array}$ & 0.003 \\
\hline & $\leq 26$ & $\begin{array}{l}8806.88 \\
{[7168.05 ; 10,445.71]}\end{array}$ & $\begin{array}{l}6177.61 \\
{[4910.61 ; 7444.61]}\end{array}$ & $\begin{array}{l}10,722.14 \\
{[8056.68 ; 13,387.60]}\end{array}$ & 0.003 \\
\hline \multirow[t]{2}{*}{ Barthel } & $=100$ & $\begin{array}{l}7606.17 \\
{[6308.04 ; 8904.29]}\end{array}$ & $\begin{array}{l}6010,14 \\
{[5353.20 ; 6667.07]}\end{array}$ & $\begin{array}{l}9321.38 \\
{[6728.13 ; 11,914.63]}\end{array}$ & 0.015 \\
\hline & $<100$ & $\begin{array}{l}11,265.07 \\
{[9061.46 ; 13,468.67]}\end{array}$ & $\begin{array}{l}8947.26 \\
{[3573.22 ; 14,321.30]}\end{array}$ & $\begin{array}{l}11,705.71 \\
{[9279.13 ; 14,132.30]}\end{array}$ & 0.352 \\
\hline \multirow[t]{2}{*}{$\mathrm{CCI}$} & $>2$ & $\begin{array}{l}10,969.58 \\
{[8696.58 ; 13,242.58]}\end{array}$ & $\begin{array}{l}7099.45 \\
{[5141.80 ; 9057.10]}\end{array}$ & $\begin{array}{l}13,031.87 \\
{[9722.97 ; 16,340.76]}\end{array}$ & 0.003 \\
\hline & $\leq 2$ & $\begin{array}{l}6928.85 \\
{[6178.80 ; 7678.89]}\end{array}$ & $\begin{array}{l}5918.07 \\
{[5199.97 ; 6636.18]}\end{array}$ & $\begin{array}{l}7742.48 \\
{[6522.16 ; 8962.81]}\end{array}$ & 0.012 \\
\hline \multirow[t]{6}{*}{ Surgical discipline } & Orthopedic & $\begin{array}{l}9304.33 \\
{[8275.65 ; 10,333.01]}\end{array}$ & $\begin{array}{l}6849.60 \\
{[6118.08 ; 7581.12]}\end{array}$ & $\begin{array}{l}10,162.94 \\
{[8813.01 ; 11,512.86]}\end{array}$ & 0.001 \\
\hline & Urology & $\begin{array}{l}5889.30 \\
{[5241.61 ; 6536.98]}\end{array}$ & $\begin{array}{l}6176.73 \\
{[5362.83 ; 6990.64]}\end{array}$ & $\begin{array}{l}5590.91 \\
{[4565.81 ; 6616.02]}\end{array}$ & 0.374 \\
\hline & Otorhinolaryngology & $\begin{array}{l}3834.32 \\
{[2160.84 ; 5570.81]}\end{array}$ & $\begin{array}{l}2473.79 \\
{[2196.74 ; 2750.85]}\end{array}$ & $\begin{array}{l}5054.10 \\
{[1882.26 ; 8225.95]}\end{array}$ & 0.111 \\
\hline & General/visceral & $\begin{array}{l}18,669.64 \\
{[12,924.44 ; 24.414 .84]}\end{array}$ & $\begin{array}{l}12,287.30 \\
{[7543.71 ; 17,030.88]}\end{array}$ & $\begin{array}{l}22,837.69 \\
{[13,878.06 ; 31,797.32]}\end{array}$ & 0.040 \\
\hline & Gynecology & $\begin{array}{l}6789.41 \\
{[4172.97 ; 9405.86]}\end{array}$ & $\begin{array}{l}5235.51 \\
{[3629.31 ; 6841.72]}\end{array}$ & $\begin{array}{l}8126.49 \\
{[3397.08 ; 12,855.90]}\end{array}$ & 0.276 \\
\hline & Other & $\begin{array}{l}4169.87 \\
{[3667.27 ; 4672.47]}\end{array}$ & $\begin{array}{l}3741.87 \\
{[3211.79 ; 4271.94]}\end{array}$ & $\begin{array}{l}4597.87 \\
{[3732.12 ; 5463.61]}\end{array}$ & 0.081 \\
\hline \multirow[t]{3}{*}{ Smoking status } & Yes, active & $\begin{array}{l}6905.16 \\
{[5530.30 ; 8280.02]}\end{array}$ & $\begin{array}{l}5223.20 \\
{[3864.50 ; 6581.90]}\end{array}$ & $\begin{array}{l}8303.16 \\
{[6070.98 ; 10,535.33]}\end{array}$ & 0.027 \\
\hline & No, quit & $\begin{array}{l}8189.73 \\
{[6823.29 ; 9556.17]}\end{array}$ & $\begin{array}{l}6239.08 \\
{[5464.44 ; 7013.71]}\end{array}$ & $\begin{array}{l}9622.24 \\
{[7333.30 ; 11,911.19]}\end{array}$ & 0.006 \\
\hline & No, never & $\begin{array}{l}9802.30 \\
{[7788.60 ; 11,815.99]}\end{array}$ & $\begin{array}{l}6947.29 \\
{[5167.84 ; 8726.74]}\end{array}$ & $\begin{array}{l}11,466.14 \\
{[8459.83 ; 14,472.45]}\end{array}$ & 0.011 \\
\hline \multicolumn{2}{|c|}{ Polypharmacy (>5 drugs) } & $\begin{array}{l}11,392.94 \\
{[9130.33 ; 13,655.54]}\end{array}$ & $\begin{array}{l}7472.60 \\
{[4937.87 ; 10,007.33]}\end{array}$ & $\begin{array}{l}12,806.63 \\
{[9874.95 ; 15,738.31]}\end{array}$ & 0.007 \\
\hline \multicolumn{2}{|l|}{ Happy } & $\begin{array}{l}8779.51 \\
{[7486.71 ; 10,072.30]}\end{array}$ & $\begin{array}{l}6422.54 \\
{[5469.90 ; 7375.18]}\end{array}$ & $\begin{array}{l}10,612.71 \\
{[8447.77 ; 12,777.64]}\end{array}$ & 0.001 \\
\hline \multicolumn{2}{|l|}{ Total } & $\begin{array}{l}8809.15 \\
{[7672.97 ; 9945.32]}\end{array}$ & $\begin{array}{l}6395.59 \\
{[5499.40 ; 7291.77]}\end{array}$ & $\begin{array}{l}10,419.60 \\
{[8631.70 ; 12,207.49]}\end{array}$ & 0.001 \\
\hline
\end{tabular}

Mean and in square brackets [] 95\% confidence interval are given; $p$ value: $t$-test two-tailed; bold values $p<0.05$

patients were significantly older, more often female, had a lower Barthel Index, more often underwent orthopedic or urological surgeries, more often qualified for polypharmacy $(>5$ drugs), had experienced a longer stay, more complications, and were less happy.
Based on the calculated propensity scores, we performed independent-sample $t$-tests to determine the frailty effect on costs with and without matching. The results in Table 8 show a significant difference between costs for non-frail versus (pre-)frail patients. The average cost difference between non- 
Table 5 Individual patient attributes by frailty status

\begin{tabular}{llll}
\hline & All patients & Happy $=0$ & Happy $=1$ \\
\hline Non-frail & $381(40.0 \%)$ & $24(6.3 \%)$ & $357(93.7 \%)$ \\
(Pre-)frail & $571(60.0 \%)$ & $112(19.6 \%)$ & $459(80.4 \%)$ \\
Total & $952(100 \%)$ & $136(14.3 \%)$ & $816(85.7 \%)$ \\
\hline
\end{tabular}

Absolute frequencies $(N)$ and in brackets the relative frequencies are given

frail and (pre-)frail patients was 3583.01 EUR in the propensity score-matched sample. It was 4024.01 EUR in the unmatched sample. The effect size Cohen's $d$ (Cohen 1988) is 0.26 in the matched sample; it was 0.24 in the unmatched sample, accounting for a weak but considerable relationship.

\section{Discussion}

\section{Barriers to implementation and coping strategies}

Our analysis has underlined the importance of the barrier categories identified in Harst et al. (2019), deepening the work by van Dyk (2014). Our research has identified three challenges which emerged from the consequential implementation of a value-based health care approach, namely consideration of the cost perspective, the patient-centric perspective, and the integrative perspective, complementing the medical perspective

Table 6 Regression on happiness by frailty status and covariates

\begin{tabular}{lll}
\hline & $\begin{array}{l}\text { Model 1 } \\
\text { Controls only }\end{array}$ & $\begin{array}{l}\text { Model 2 } \\
\text { (Pre-)frail }\end{array}$ \\
\hline Independ. var. & DV=happiness & \\
(Pre-)frail_bin & & $-1.045^{* * *}$ \\
& & $(0.352)$ \\
Covariates & & \\
Gender & -0.192 & -0.131 \\
& $(0.825)$ & $(0.877)$ \\
Barthel $<100$ & $1.026^{* * *}$ & $0.757 * * *$ \\
& $(2.790)$ & $(2.132)$ \\
Comorbid. $\geq 1$ & -0.341 & -0.311 \\
& $(0.711)$ & $(0.733)$ \\
Age & 0.01 & 0.014 \\
& $(1.001)$ & $(1.014)$ \\
Intercept & 1.653 & 1.528 \\
& $(5.221)$ & $(4.608)$ \\
$\mathrm{N}$ & 952 & 952 \\
$\mathrm{df}$ & 3 & 4 \\
Pseudo- $\mathrm{R}^{2}$ & 0.063 & 0.098 \\
\hline${ }^{\dagger} p<0.10 *{ }^{2} p<0.05, * p<0$ & $0.01, * * * p<0.001$, in brackets (): Odds \\
ratio & &
\end{tabular}

identified in earlier work (Birkelbach et al. 2019). From the analysis it became clear that these three dimensions represent overarching goals guiding the implementation. Making progress in each of these dimensions meant coping with deepseated organizational, technical, end-user acceptance, and economic obstacles. Organizationally, it became clear that implementing the approaches meant implementing new means of evaluation, quality management, and measurement, and also that of collecting data that was previously untapped or scattered across different information systems. Technically, it required creating new tools, such as a research study database, or desktop application solutions to support information gathering and analysis as well as the integration of information from different information systems. From an end-user acceptance viewpoint, while the initially implemented solutions focused on medical outcomes, consideration of the patient perspective required additional digital health solutions such as developing a tablet app for nurse assistants and a mobile app for patient self-assessment. Economically, it became clear that varying incentives for usage of the approach hindered widespread adoption of the approach, such that feasibility studies demonstrating the utility of the approach were necessary to foster stakeholder buy-in.

Reflecting on the progress achieved so far, it becomes clear that implementing a value-based health care approach using digital health solutions should be considered as a process. Our study shows that each of the steps taken along the implementation process face barriers and tensions that may not be easy to resolve. The successful implementation of the approach meant finding ways to cope with these tensions rather than resolving them completely. Adding constant reflections on possible challenges and barriers arising further maximizes the chance of continuous progress. For instance, whereas the full-scale implementation of the approach within all steps involving different clinics would have been desirable, it was easier to initially emulate the approach within one clinic in order to demonstrate its potential and roll it out on a more widespread basis in a later step. Against this background, future work could thus consider tensions and barriers in this process in more detail by adopting a dialectical or paradoxical process perspective (Smith and Lewis 2011; Cloutier and Langley 2020).

\section{Potentials of value-based health care approach to tackle the frailty burden}

We have created initial evidence for the usefulness of an integrative value-based health care approach for tackling the frailty burden in perioperative care. The results show that costs in inpatient treatment are significantly associated with frailty status. Prevalence of frailty was $11.8 \%$ (frail) and $48.2 \%$ (prefrail), which is slightly higher than in previous studies (e.g. systematic review by Collard et al. 2012). In a similar study 
Table 7 Propensity score matching

\begin{tabular}{|c|c|c|c|c|c|c|}
\hline & \multicolumn{3}{|c|}{ All patients $(n=952)$} & \multicolumn{3}{|c|}{ PS-Matched patients $(n=762)$} \\
\hline & $\begin{array}{l}\text { Non-frail } \\
(n=381)\end{array}$ & $\begin{array}{l}\text { (Pre-)frail } \\
(n=571)\end{array}$ & $p$ value & $\begin{array}{l}\text { Non-frail } \\
(n=381)\end{array}$ & $($ Pre-)frail $(n=381)$ & $p$ value \\
\hline Age & $\begin{array}{l}71.85 \\
{[71.39 ; 72.31]}\end{array}$ & $\begin{array}{l}74.67 \\
{[74.19 ; 75 ; 15]}\end{array}$ & 0.001 & $71.85[71.39 ; 72.31]$ & $\begin{array}{l}74.52 \\
{[73.93 ; 75.11]}\end{array}$ & 0.001 \\
\hline Male & $223(59 \%)$ & $281(49 \%)$ & 0.005 & $223(58.5 \%)$ & $193(50.7 \%)$ & 0.029 \\
\hline BMI & $\begin{array}{l}26.60 \\
{[26.15 ; 27.04]}\end{array}$ & $\begin{array}{l}26.95 \\
{[26.54 ; 27.36}\end{array}$ & 0.275 & $\begin{array}{l}26.60 \\
{[26.15 ; 27.04]}\end{array}$ & $\begin{array}{l}27.02 \\
{[26.51 ; 27.53]}\end{array}$ & 0.223 \\
\hline Barthel Index & $\begin{array}{l}98.78 \\
{[98.32 ; 99.24]}\end{array}$ & $\begin{array}{l}90.14 \\
{[88.82 ; 91.46]}\end{array}$ & 0.001 & $\begin{array}{l}98.78 \\
{[98.32 ; 99.24]}\end{array}$ & $\begin{array}{l}89.76 \\
{[88.06 ; 91.46]}\end{array}$ & 0.001 \\
\hline $\mathrm{CCI}$ & $\begin{array}{l}2.61 \\
{[2.37 ; 2.86]}\end{array}$ & $\begin{array}{l}3.26 \\
{[3.00 ; 3.51]}\end{array}$ & 0.001 & $\begin{array}{l}2.61 \\
{[2.37 ; 2.86]}\end{array}$ & $\begin{array}{l}3.35 \\
{[3.02 ; 3.68]}\end{array}$ & 0.001 \\
\hline Surgical discipline & & & & & & \\
\hline Orthopedic & $78(20.5 \%)$ & $223(39.1 \%)$ & 0.001 & $78(20.5 \%)$ & $154(40.4 \%)$ & 0.001 \\
\hline Urology & $109(28.6 \%)$ & $105(18.4 \%)$ & 0.001 & $109(28.6 \%)$ & $70(18.4 \%)$ & 0.001 \\
\hline Otorhinolaryngology & $78(20.5 \%)$ & $87(15.2 \%)$ & 0.037 & $78(20.5 \%)$ & $52(13.6 \%)$ & 0.012 \\
\hline General/visceral & $64(16.8 \%)$ & $98(17.2 \%)$ & 0.883 & $64(16.8 \%)$ & $68(17.8 \%)$ & 0.702 \\
\hline Gynecology & $37(9.7 \%)$ & $43(7.5 \%)$ & 0.235 & $37(9.7 \%)$ & $26(6.8 \%)$ & 0.148 \\
\hline $\begin{array}{l}\text { Other } \\
\text { Smoking status }\end{array}$ & $15(3.9 \%)$ & $15(2.6 \%)$ & 0.257 & $15(3.9 \%)$ & $11(2.9 \%)$ & 0.425 \\
\hline Yes, active & $64(16.8 \%)$ & $77(13.5 \%)$ & 0.159 & $64(16.8 \%)$ & $55(14.4 \%)$ & 0.370 \\
\hline No, quit & $141(37.0 \%)$ & $192(33.6 \%)$ & 0.284 & $141(37.0 \%)$ & $128(33.6 \%)$ & 0.325 \\
\hline No, never & $176(46.2 \%)$ & $302(52.9 \%)$ & 0.043 & $176(46.2 \%)$ & $198(52.0 \%)$ & 0.111 \\
\hline Polypharmacy (> 5 drugs) & $119(31.2 \%)$ & $330(57.8 \%)$ & 0.001 & $119(31.2 \%)$ & $227(59.6 \%)$ & 0.001 \\
\hline Length of stay (LoS) & $\begin{array}{l}7.93 \\
{[7.37 ; 8.49]}\end{array}$ & $\begin{array}{l}10.97 \\
{[10.18 ; 11.75]}\end{array}$ & 0.001 & $\begin{array}{l}7.93 \\
{[7.37 ; 8.49]}\end{array}$ & $\begin{array}{l}11.02 \\
{[10.24 ; 11.81]}\end{array}$ & 0.001 \\
\hline Complications & $63(16.5 \%)$ & $197(34.5 \%)$ & 0.001 & $63(16.5 \%)$ & $131(34.4 \%)$ & 0.001 \\
\hline Happiness & $357(93.7 \%)$ & $459(80.4 \%)$ & 0.001 & $357(93.7 \%)$ & $309(81.1 \%)$ & 0.001 \\
\hline
\end{tabular}

also using the Fried criteria to determine frailty status, Saum et al. (2012) found prevalence of frailty as $58 \%$ pre-frail and $8.9 \%$ frail. The values obtained are probably higher due to the fact that assessment took place within a university hospital setting for patients scheduled for surgery, while other studies had occurred in a routine setting.

While previous research has considered medical outcomes, showing frailty to be associated with postoperative complications (e.g., Birkelbach et al. 2019), the cost, patient, and integrative perspective has so far only received limited attention. Sirven and Rapp (2017) discuss the outpatient costs for patients 65 years of age and older in the French health care system during 2012 and differentiate them according to frailty categories. According to this study, pre-frail patients incur an additional 750 EUR and frail patients 1500 EUR in expenses on average. Our study finds additional costs of 3583.01 [1654.92; 5511.04] EUR for (pre-)frail patients. These are inpatient costs in the hospital and do not amount to the entire frailty burden. Having demonstrated that frailty is associated with significantly higher costs should motivate care deliverers to consider costs in a broader context.

We have also shown how additional assessment categories, for instance, happiness, can add to the patient perspective measuring important aspects of the individual patient status. As we could only access data on the general psychological status of our study population, results on disease-specific indicators are missing and should be investigated in more detail during the process of collecting data as, for instance, by using standardized outcome sets such as the ones by ICHOM (2021). We could show significant differences in costs depending on individual patient characteristics in terms of happiness, which further research should explore in more detail. Further research should also determine ways to constantly track patient-centric outcome measures in the perioperative process related to frailty as was piloted through the described patient app.
Table 8 Frailty effect on costs with/without matching

\begin{tabular}{llllll}
\hline & $\begin{array}{l}\text { Non- } \\
\text { frail }\end{array}$ & (Pre-)frail & T & $\begin{array}{l}\text { Diff. avg. } \\
{[95 \% \mathrm{CI}]}\end{array}$ & $p$ value \\
\hline Without matching & 6395.59 & $10,419.60$ & -3.953 & $\begin{array}{l}4024.01 \\
{[2025.78 ; 6022.24]}\end{array}$ & $\mathbf{0 . 0 0 1}$ \\
Propensity score matching & 6395.59 & 9978.59 & -3.650 & $\begin{array}{l}3583.01 \\
{[1654.92 ; 5511.04]}\end{array}$ & \\
\hline
\end{tabular}




\section{Limitations}

The main limitations of the study were as follows: Firstly, probands in the retrospective observational study were not selected at random, and therefore we used propensity score matching. Propensity score matching does not fully compensate for non-randomization, calling for future controlled trials. Secondly, while variables such as polypharmacy were assessed, the information came from patient self-reports; it was not recorded, for instance, which medications were used that might correlate with frailty or relevant study outcomes. Since some medications pose higher risks for elderly and frail patients (e.g., Holt et al. 2010), this should be relevant information for interventional studies. Thirdly, the included patientreported measures only reflected a selection of important possible measures and should be extended in the future by data on measures of emotional health (beyond happiness), loneliness and isolation, pain, and autonomy (see e.g., ICHOM 2021 quality of life outcomes for elderly person). Finally, while we could access rich qualitative data, further formal interviews could provide further insights if they add other groups such as patients.

\section{Conclusion}

This study considered the implementation of value-based health care principles in the context of frailty in the perioperative process vis-à-vis digital health solutions. Based on a sequential mixed-methods study, we first qualitatively identified three challenges when implementing a valuebased health care approach in the context of elderly adults undergoing surgery, namely (1) the appropriate consideration of related costs, (2) a patient-centric outcome, and (3) an integrative perspective. Demonstrating the value of such an approach in the context of Charité's Department of Anesthesiology and Intensive Care Medicine, we have used quantitative data from $n=952$ patients and processed them via propensity score matching to show additional frailty-associated costs in inpatient treatment as well as the influence of individual patient-centric attributes.

In the future, it will be desirable to include both medical and patient-reported outcomes and costs in one integrative solution, which coincides with a current project to scale this assessment towards other settings and to take preparatory actions for patients identified as having high postoperative risks. These next steps will also require tackling further barriers, including collaboration between ambulant and clinical stakeholders, interprofessional collaboration, and capacity constraints, which have initially led to coping strategies such as integrating the assessment-related activities into the workflow of one clinic that could mobilize the resources to carry it out.

Acknowledgements We would like to thank five medical doctoral candidates (ALH, JK, HR, IW, JW) for their assistance in data collection, as well as Kathrin Scholtz for her assistance in project management and quality assurance. We thank Gina Genseler for support regarding the patient-centric apps within her Bachelor thesis. Dr. Oliver Birkelbach made important contributions in setting up the frailty assessment questionnaire/procedure.

Author's contribution DF, HMH and FB conceptualized the work. DF, TW, KS and FB conceived the methodology. DF, TW and KS carried out the formal analysis and investigation. DF and $\mathrm{HMH}$ wrote the original draft; all other authors reviewed and edited the draft. CS acquired funding and resources for the project. DF and FB supervised TW within the original scope of the project.

Funding Open Access funding enabled and organized by Projekt DEAL. The analysis is part of a quality improvement effort from the Department of Anesthesiology and Operative Intensive Care Medicine of the Charité Universitätsmedizin - Berlin, Campus Mitte and Virchow-Klinikum. No external funding was required for it. Daniel Fürstenau and Felix Balzer received funding from the Einstein Foundation for independent research within the broad area of research, which is thankfully acknowledged.

Data availability The data sets used and analyzed during the current study are available from the corresponding author on reasonable request.

\section{Declarations}

Conflict of interest The authors have no relevant conflicts of interest to disclose.

Ethics approval The analysis was covered by the ethics committee (EA1/227/16) of the Charité Universitätsmedizin - Berlin, Berlin, Germany.

Consent to participate Not applicable.

Consent for publication Not applicable.

\section{Appendix}

Appendix 1 - Flow Chart

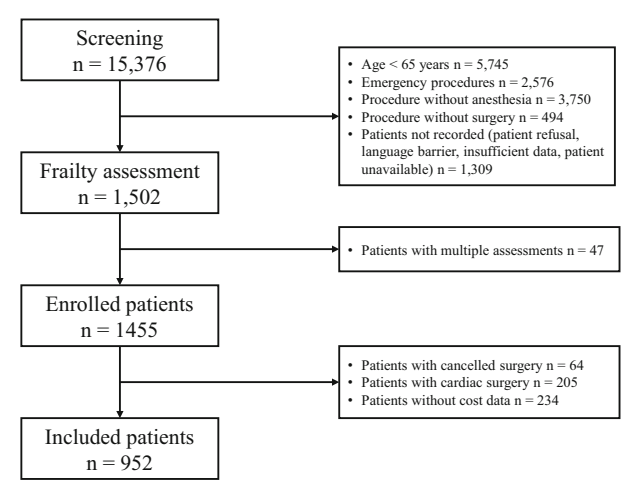


Open Access This article is licensed under a Creative Commons Attribution 4.0 International License, which permits use, sharing, adaptation, distribution and reproduction in any medium or format, as long as you give appropriate credit to the original author(s) and the source, provide a link to the Creative Commons licence, and indicate if changes were made. The images or other third party material in this article are included in the article's Creative Commons licence, unless indicated otherwise in a credit line to the material. If material is not included in the article's Creative Commons licence and your intended use is not permitted by statutory regulation or exceeds the permitted use, you will need to obtain permission directly from the copyright holder. To view a copy of this licence, visit http://creativecommons.org/licenses/by/4.0/.

\section{References}

Baskerville RL (1999) Investigating information systems with action research. Commun AIS 2:19. https://doi.org/10.17705/icais.00219

Becker H, Geer B (1957) Participant observation and interviewing: a comparison. Hum Organ 16:28-32. https://doi.org/10.17730/ humo.16.3.k687822132323013

Birkelbach O, Mörgeli R, Balzer F, Olbert M, Treskatsch S, Kiefmann R et al (2017) Warum und wie sollte ich Frailty erfassen? - ein Ansatz für die Anästhesieambulanz. AINS - Anästhesiologie, Intensivmedizin, Notfallmedizin, Schmerztherapie 52:765-776. https://doi.org/10.1055/s-0043-104682

Birkelbach O, Mörgeli R, Spies C, Olbert M, Weiss B, Brauner M, Neuner B, Francis RCE, Treskatsch S, Balzer F (2019) Routine frailty assessment predicts postoperative complications in elderly patients across surgical disciplines - a retrospective observational study. BMC Anesthesiol 19:204. https://doi.org/10.1186/s12871019-0880-x

Buckinx F, Rolland Y, Reginster JY, Ricour C, Petermans J, Bruyère O (2015) Burden of frailty in the elderly population: perspectives for a public health challenge. Arch Public Heal 73:19. https://doi.org/10. 1186/s13690-015-0068-x

Charlson ME, Pompei P, Ales KL, MacKenzie CR (1987) A new method of classifying prognostic comorbidity in longitudinal studies: development and validation. J Chronic Dis 40:373-383. https://doi.org/ 10.1016/0021-9681(87)90171-8

Chaudhary M (2018) Association of food insecurity with frailty among older adults in India. Aust J Public Health 26:321-330. https://doi. org/10.1007/s10389-017-0866-4

Cloutier C, Langley A (2020) What makes a process theoretical contribution? Organ Theory 1:1-32. https://doi.org/10.1177/ 2631787720902473

Cohen J (1988) Statistical power analysis for the behavioral sciences. Routledge Academic, New York

Collard RM, Boter H, Schoevers RA, Oude Voshaar RC (2012) Prevalence of frailty in community-dwelling older persons: a systematic review. J Am Geriatr Soc 60:1487-1492. https://doi.org/10. 1111/j.1532-5415.2012.04054.x

Creswell JW, Creswell JD (2018) Research design: qualitative, quantitative, and mixed methods approaches, 5th edn. Sage Publications, Thousand Oaks

Dedeyne L, Deschodt M, Verschueren S, Tournoy J, Gielen E (2017) Effects of multi-domain interventions in (pre)frail elderly on frailty, functional, and cognitive status: a systematic review. Clin Interv Aging 12:873-896. https://doi.org/10.2147/CIA.S130794

Dent E, Hoogendijk EO (2014) Psychosocial factors modify the association of frailty with adverse outcomes: a prospective study of hospitalised older people. BMC Geriatr 14:108. https://doi.org/10. 1186/1471-2318-14-108

Dewey M (2018) The future of radiology: adding value to clinical care. Lancet 392(10146):472-473. https://doi.org/10.1016/S01406736(18)31193-0

Feinkohl I, Winterer G, Pischon T (2017) Hypertension and risk of postoperative cognitive dysfunction (POCD): a systematic review and meta-analysis. Clin Pract Epidemiol Ment Health 13:27-42. https:// doi.org/10.2174/1745017901713010027

Freitag S, Schmidt S (2016) Psychosocial correlates of frailty in older adults. Geriatrics 1:26. https://doi.org/10.3390/geriatrics1040026

Freitag S, Schmidt S, Gobbens RJJ (2016) Tilburg Frailty Indicator: Eine deutsche Übersetzung und psychometrische Testung. Z Gerontol Geriatr 49:86-93. https://doi.org/10.1007/s00391-015-0889-9

Fried LP, Tangen CM, Walston J et al (2001) Frailty in older adults: evidence for a phenotype. J Gerontol Ser A Biol Sci Med Sci 56: M146-M156. https://doi.org/10.1093/gerona/56.3.m146

Fürstenau D, Spies C, Gersch M, Vogel A, Mörgeli R, Poncette AS, Müller-Werdan U, Balzer F (2019) Sharing frailty-related information in perioperative care: an analysis from a temporal perspective. BMC Health Serv Res 19:105. https://doi.org/10.1186/s12913-0193890-y

Harris PA, Taylor R, Thielke R, Payne J, Gonzalez N, Conde JG (2009) Research electronic data capture (REDCap)-a metadata-driven methodology and workflow process for providing translational research informatics support. J Biomed Inform 42:377-381. https:// doi.org/10.1016/j.jbi.2008.08.010

Harst L, Timpel P, Otto L, Richter P, Wollschlaeger B, Winkler K, Schlieter H (2019) Identifying barriers in telemedicine-supported integrated care research: scoping reviews and qualitative content analysis. Aust J Public Health 28:583-594. https://doi.org/10. 1007/s10389-019-01065-5

Holt S, Schmiedl S, Thürmann PA (2010) Potentially inappropriate medications in the elderly: the PRISCUS list. Dtsch Arztebl Int 107:543551. https://doi.org/10.3238/arztebl.2010.0543

ICHOM (2021) International Consortium for Health Outcome Measures. https://www.ichom.org. Accessed 14 May 2021

Karsten MM, Speiser D, Hartmann C, Zeuschner N, Lippold K, Kiver V, Gocke P, Kirchberger V, Blohmer JU (2018) Web-based patientreported outcomes using the international consortium for health outcome measurement dataset in a major German university hospital: observational study. JMIR Cancer 4(2):e11373. https://doi.org/10. 2196/11373

Langley A (1999) Strategies for theorizing from process data. Acad Manag Rev 24:691-710. https://doi.org/10.5465/AMR.1999. 2553248

Liu CK, Fielding RA (2011) Exercise as an intervention for frailty. Clin Geriatr Med 27:101-110. https://doi.org/10.1016/j.cger.2010.08. 001

Mahoney FI, Barthel DW (1965) Functional evaluation: the Barthel index: a simple index of independence useful in scoring improvement in the rehabilitation of the chronically ill. Maryland State Med J 14: $61-65$

Miles MB, Huberman AM (1994) Qualitative data analysis: an expanded sourcebook, 2nd edn. Sage Publications, Thousand Oaks

Porter ME (2008) Value-based health care delivery. Ann Surg 248:503509. https://doi.org/10.1097/SLA.0b013e31818a43af

Porter ME, Teisberg EO (2006) Redefining health care: creating valuebased competition on results. Harvard Business Review Press, Boston

Saum KU, Müller H, Stegmaier C, Hauer K, Raum E, Brenner H (2012) Development and evaluation of a modification of the fried frailty 
criteria using population-independent cutpoints. J Am Geriatr Soc 60:2110-2115. https://doi.org/10.1111/j.1532-5415.2012.04192.x

Schreyögg J, Tiemann O, Busse R (2006) Cost accounting to determine prices: how well do prices reflect costs in the German DRG-system? Health Care Manag Sci 9:269-279. https://doi.org/10.1007/s10729006-9094-0

Sirven N, Rapp T (2017) The cost of frailty in France. Eur J Health Econ 18:243-253. https://doi.org/10.1007/s10198-016-0772-7

Smith W, Lewis M (2011) Toward a theory of paradox: a dynamic equilibrium model of organizing. Acad Manag Rev 36:381-403. https:// doi.org/10.5465/amr.2009.0223

Statistisches Bundesamt (2018) Fallpauschalenbezogene Krankenhausstatistik (DRG-Statistik) Operationen und Prozeduren der vollstationären Patientinnen und Patienten in Krankenhäusern. https://www.destatis.de/DE/Themen/Gesellschaft-Umwelt/ Gesundheit/Krankenhaeuser/Publikationen/Downloads-
Krankenhaeuser/operationen-prozeduren-5231401187014.html. Accessed 14 May 2021

van Dyk L (2014) A review of telehealth service implementation frameworks. Int J Environ Res Public Health 11:1279-1298. https://doi. org/10.3390/ijerph1 10201279

Winterer G, Androsova G, Bender O et al (2018) Personalized risk prediction of postoperative cognitive impairment - rationale for the EUfunded BioCog project. Eur Psychiatry 50:34-39. https://doi.org/10. 1016/j.eurpsy.2017.10.004

Xue QL (2011) The frailty syndrome: definition and natural history. Clin Geriatr Med 27:1-15. https://doi.org/10.1016/j.cger.2010.08.009

Publisher's note Springer Nature remains neutral with regard to jurisdictional claims in published maps and institutional affiliations. 